\title{
Peer assisted learning at the Department of Chemistry for home and international students
}

\section{Gita Sedghi}

University of Liverpool, UK

\section{Corresponding author:}

Gita Sedghi, Department of Chemistry, University of Liverpool, Liverpool L69 7ZD, UK Email: G.Sedghi@liverpool.ac.uk

\begin{abstract}
Peer assisted learning (PAL) was implemented in the Chemistry Department at the University of Liverpool to complement the University's current peer mentoring programme. PAL leaders, who were trained by the staff from the Educational Development Division, took over the role of giving subject and pastoral support to first year undergraduate students and second year international students.

The scheme was initially set up to support first year chemistry undergraduate students with modules in mathematics and organic chemistry. After a short period it was extended to cover more modules and to support second year home students as well as first year students. First year students believed that PAL sessions were extremely useful to help them adapt to their new university life. The scheme was also set up to support international students from China entering directly into second year undergraduate studies at Liverpool. The study sessions were initially organised to support them with general key skills. International students found the PAL sessions extremely useful and requested that chemistry practical courses be included in the scheme. The successful PAL scheme in the Department of Chemistry shows the importance of student participation in enhancing teaching and learning activities in undergraduate programmes.
\end{abstract}

Keywords: peer assisted learning, peer mentoring, international students, collaborative learning

\section{Introduction}

Peer Assisted Learning (PAL), which is a student-to-student support scheme, was implemented in the Chemistry 
Department at the University of Liverpool in September 2012 and complements the university's existing Peer Mentoring Programme. The project was funded by the HE STEM programme. Its aim initially was to support first year undergraduate students in adjusting to university life and also to help them with a mathematics module, which is one of the subjects chemistry students find most difficult. The scheme also supported international students from China. After less than a year PAL was extended to cover more chemistry modules in the first year and the second year undergraduate course. This proved the success and sustainability of the scheme.

Chemistry PAL leaders give both pastoral and subject support to lower year students. They not only plan and run the study sessions, but they are also involved in other teaching and learning activities, including acting as student helpers at university open days. PAL leaders, who are in contact with international students before their arrival in Liverpool, organise social activities to enhance integration by international students with their home counterparts. PAL leaders play an important role in running various activities during Welcome Week, including library tours and tutorials on the university's virtual learning environment.

Peer assisted learning in the Chemistry Department enhances teaching and learning activities, such as collaborative learning, develops PAL leaders' leadership and employment skills, and helps home and international students to adapt to the new academic environment. The evaluation of the PAL scheme in the department showed the importance of a system based on the requirements of the course and of maintenance and development. PAL leaders are key to a successful scheme; the success of Liverpool's PAL system illustrates the role of student participation in enhancing teaching and learning activities.

\section{Method}

\section{PAL structure}

The project enabled the chemistry academic staff to study PAL schemes at other universities and to implement a system based on the requirements of the department and its chemistry programmes. Undergraduate students were involved in setting up the scheme from the early stages of the project. Several useful ideas and suggestions on how to implement the system were contributed by our undergraduate students in focus groups and interviews organised by academic staff. The involvement of undergraduate students at every step of the project gave them confidence that the system belongs to them, that it is run for them and that it is run by them.
Peer mentoring and peer assisted learning complement each other. Each PAL leader takes on the role of giving pastoral support to a group of five to six students. The leaders meet the mentees during the Welcome Week and stay in contact via email or short meetings to make sure the new students are adjusting to university life and the new academic system.

Due to the restrictions imposed by timetabling on the availability of teaching space, we could not assign individual rooms to each group of students and their PAL leader. Therefore, one weekly PAL session is scheduled for about hundred first year and twenty second year students in a large seminar room to avoid any clashes with other teaching sessions. Each PAL leader, or a pair of leaders, facilitates roundtable discussions in a group of five to seven students. Each weekly study session covers different modules and topics depending on course requirements and students' performance. Attendance for students is optional and topics are advertised a week in advance. Students book the sessions via the online booking system and the number of PAL leaders assigned for weekly sessions depends on the number of student participants.

The PAL scheme was initially set up to support first year students with the mathematics module, which is one of the most challenging subjects for chemistry students, especially for those without A-level mathematics. Mathematics workshop questions are split into three levels: basic, intermediate and advanced. However, students at the basic and intermediate levels not only struggle with the mathematics but are also usually disadvantaged in the physical chemistry modules. We believed that peer support could help these students to understand this difficult topic and, more importantly, to gain confidence that they would be able to improve their mathematical skills.

After a short while students who found the mathematics study sessions useful asked academic staff to include other chemistry modules in the PAL scheme. As a result, inorganic and physical chemistry modules were added. It is noteworthy that when the scheme was extended to cover the second year spectroscopy and quantum mechanics modules during the second semester as requested by students even the second year PAL leaders joined the study sessions as student participants.

Our initial studies on the performance of international students highlighted the requirement for support with study skills modules. The third year PAL leaders assisted our second year international students with the writing of scientific reports and essays, presentation skills and English grammar. After attending the study sessions for a few weeks, and reaping the benefits, 
international students requested additional support for practical skills.

\section{PAL leader recruitment and training}

The process of recruiting PAL leaders started six months prior to the launch of the scheme. Posters to introduce the system and to advertise the PAL leader posts were mounted on notice boards in the department. Application forms and informative leaflets were emailed to students. Although only a small number of students applied for the post, this was enough to run the scheme efficiently. To increase the number of applicants, we arranged a meeting with undergraduate students who had shown an interest in the scheme and subsequently we organised short talks by senior students in lectures in order to provide more information on the benefits of becoming a PAL leader. As a result, the number of applicants increased to twice the number required to run the system.

A one-day training during the Welcome Week was organised for successful applicants by the staff at the Educational Development Division. Thirty-four chemistry students were trained and received their certificate of attendance in training in September 2012. The trained leaders took up their role in the academic year 2012-13. A member of the chemistry staff attended a Peer Assisted Study Sessions (PASS) training at the University of Manchester and is qualified to train future PAL leaders. A one-day training event for PAL leaders is planned for the next academic year. In addition, there will be regular monthly meetings in order to give continuous support to leaders and to keep staff updated on students' progress.

\section{Results}

A peer mentoring programme has been running in the Department of Chemistry for many years. Each peer mentor was assigned between two and three first year students. Peer mentors were invited to help with the Welcome Week and introduce themselves to new students. The experience of the programme showed that any communication between mentors and mentees disappeared after the first couple of weeks of the academic year. However, after introducing PAL we decided to combine the two roles and assign five to six students to each mentor. PAL leaders believed that it was difficult to differentiate between the two roles and they will be involved in giving both pastoral and subject support to new students while acting as PAL leaders.

\section{PAL for first year students}

Evaluation of the system at the end of the academic year 2012-13 showed that only a few students continued communication via email with their assigned mentors. Most students were happy to attend the PAL sessions. Student representatives stated that first year students felt more confident with the subjects covered by the scheme; therefore, they requested an extension to cover the rest of the chemistry modules. End of year questionnaires indicated that $83 \%$ of students who attended the mathematics PAL sessions found them useful.

\section{PAL for international students}

Evaluation of the system for international students showed a very high level of satisfaction. Figure 1 shows the percentage of students who agreed that

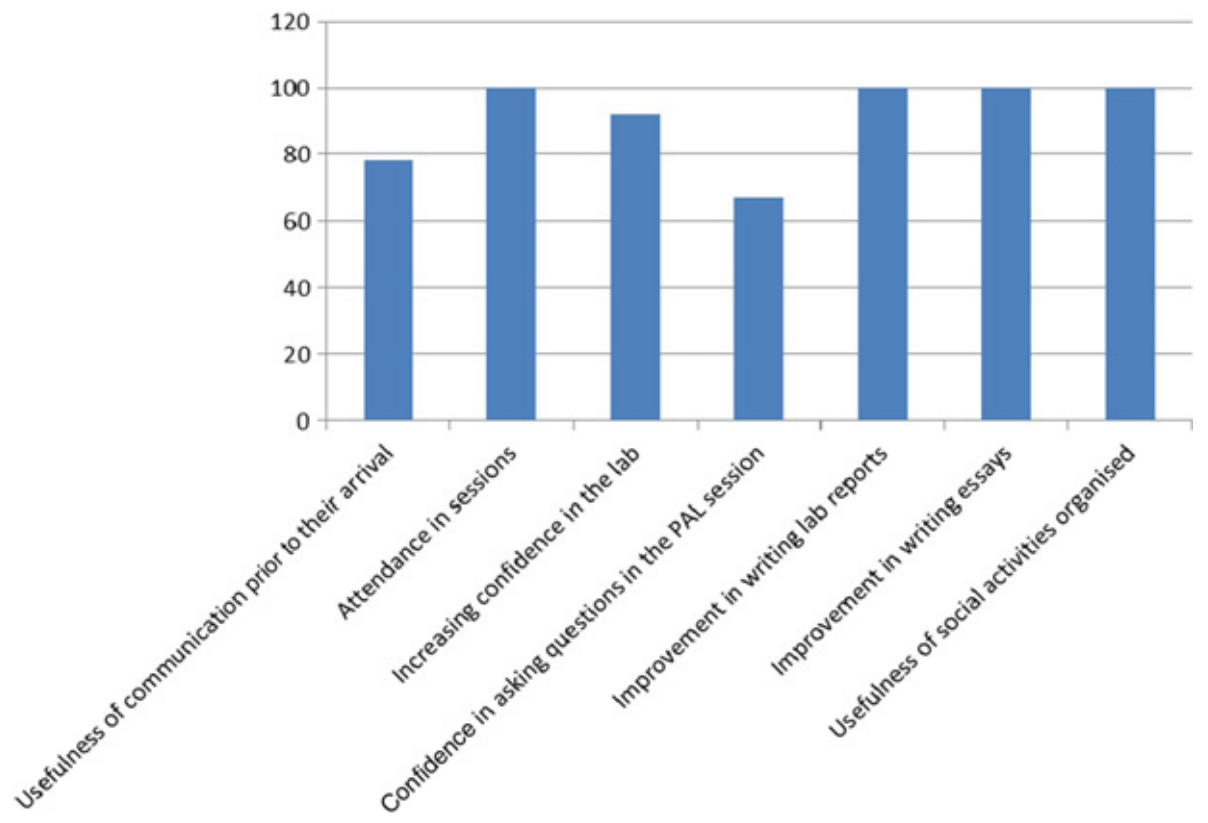

Figure 1 Results of the PAL questionnaire for first year students and second year international students 
PAL sessions helped them with different aspects of their studies and university life. The high level of satisfaction of international students illustrates the positive effect of PAL in helping students adjust to the new academic environment. Students found the sessions useful for improving their practical and study skills. However, only $67 \%$ of students felt comfortable asking questions in the sessions. This could be related to the general lack of confidence with spoken English. Confidence and language are issues for international students which stop them from communicating with home students and are issues that remain unresolved. However, the social activities organised by PAL leaders are well received by our international students. Also, international students have built a strong relationship with their third year student mentors.

It was noticed that the first year students initially needed more pastoral than subject support. After forming their friendship groups, they requested only subject support in the study sessions. However, the experience with international students was the opposite: they needed more subject support in the first semester in order to adjust to the new teaching and learning system; the study sessions helped them catch up with their studies. During the second semester, international students noted the lack of interaction with home students and asked PAL leaders to organise more social activities.

\section{Conclusion}

Peer assisted learning combined with peer mentoring for first year undergraduate students and second year international students was devised and implemented in the Department of Chemistry. The scheme had positive effects on both PAL leaders and student participants. Involving PAL leaders in implementation and maintenance of the scheme had a positive impact on leaders, helping them to understand the system better, and to become motivated and committed towards their duties. They came up with constructive ideas at each stage of the project and took responsibility for planning and running the PAL sessions. Some PAL leaders showed particular interest in working with international students and helped the first arrival of international students from China to feel welcome and to adjust to the new academic environment.

The first year chemistry students found the PAL scheme extremely useful in helping them to adjust to the chemistry programme and to university life. The international students found the scheme very beneficial and attended every session in order to improve their practical and study skills. They found the social activities organised by PAL leaders useful to help them to integrate with home students.

The successful PAL scheme showed the importance of partnership between students and staff in enhancing teaching and learning activities. PAL encourages team work and collaborative learning. It improves the leadership and employability skills of senior students. PAL leaders are proactive students who are usually involved in different teaching and learning activities. They participate in research projects, university open days, outreach activities, planning new experiments for the chemistry courses and creating new teaching resources. Such undergraduate students are key to implementing and maintaining student-to-student services including PAL. 